\title{
The apicoplast genome of Leucocytozoon caulleryi, a pathogenic apicomplexan parasite of the chicken
}

\author{
Takayuki Imura • Shigeharu Sato • Yukita Sato • \\ Daichi Sakamoto • Takashi Isobe • Koichi Murata • \\ Anthony A. Holder • Masayoshi Yukawa
}

Received: 16 August 2013 / Accepted: 18 November 2013/Published online: 4 December 2013

(C) The Author(s) 2013. This article is published with open access at Springerlink.com

\begin{abstract}
Leucocytozoon caulleryi, a haemosporidian parasite of the chicken (Gallus gallus domesticus), can be highly pathogenic and often fatal. Although this parasite is extremely relevant to veterinary science, knowledge of its genomic features is limited. To gain information applicable to developing novel control methods for the parasite, we analyzed the apicoplast genome of $L$. caulleryi. This extranuclear organellar DNA of $85.1 \% \mathrm{~A}+\mathrm{T}$ and a unit of $34,779 \mathrm{bp}$ was found to encode almost the same set of genes as the plastid genome of Plasmodium falciparum, including 16 tRNA and 30 protein coding genes, and except for one open reading frame, ORF91 absent in L. caulleryi. As in $P$. falciparum, the $L$. caulleryi apicoplast DNA contains two sets of a unique inverted repeat (IR), each one 5,253 bp and encoding genes specifying one large and one small rRNA subunit and nine tRNAs but no protein, and separated by a unique 13 bp sequence. Studies of several haemosporidian
\end{abstract}

Takayuki Imura and Shigeharu Sato contributed equally to this study.

T. Imura $\cdot$ Y. Sato $\cdot$ D. Sakamoto $\cdot$ M. Yukawa

Department of Veterinary Medicine, College of Bioresource

Sciences, Nihon University, Fujisawa, Kanagawa 252-0880, Japan

S. Sato $\cdot$ A. A. Holder

Division of Parasitology, MRC National Institute for Medical

Research, London NW7 1AA, UK

T. Isobe

National Institute of Animal Health, Tsukuba, Ibaraki 305-0856,

Japan

K. Murata

Department of Animal Resource Sciences, College of Bioresource

Sciences, Nihon University, Fujisawa, Kanagawa 252-0880, Japan

Y. Sato $(\bowtie)$

Laboratory of Biomedical Science, Department of Veterinary

Medicine, Nihon University, Fujisawa, Kanagawa 252-0880, Japan

e-mail: sato.yukita@nihon-u.ac.jp apicoplast DNA sequences have identified a corresponding IR region; however, none of these studies has looked at the complete sequence, even for well-studied species such as $P$. falciparum. Phylogenetic studies using a concatenated amino acid sequence based on the open reading frames confirmed the close relationship between L. caulleryi and Plasmodium spp. In this study, we determined the nucleotide sequence of the entire $L$. caulleryi apicoplast genome, including the region connecting the two IR units. This is the first report of the complete nucleotide sequence of a haemosporidian apicoplast DNA with a canonical IR.

\section{Introduction}

The phylum Apicomplexa consists of protistan parasites, including species of medical or veterinary importance such as Plasmodium falciparum, Toxoplasma gondii, and Eimeria tenella. One of the characteristics shared by these parasites is the presence of a vestigial plastid called the apicoplast (Foth and McFadden 2003; McFadden 2011). This plastid has been suggested to have originated from an ancient endosymbiotic alga of debated phylogenetic position (Köhler et al. 1997; Janouskovec et al. 2010). Previous studies have suggested that this organelle is involved in critical metabolic processes such as heme and isoprenoid biosynthesis (McFadden 2011; Ralph et al. 2004). Indeed, P. falciparum that has lost its apicoplast cannot grow unless the product of the apicoplastic isoprenoid biosynthesis, isopentenyl pyrophosphate, is supplemented to the culture medium (Yeh and DeRisi 2011). These studies have led to recognition of the apicoplast as a potential anti-Plasmodium drug target.

As a vestigial plastid, the apicoplast retains its own genome. To date, analysis of the apicoplast genomes of nine Plasmodium species, T. gondii, E. tenella, Theileria parva, and Babesia bovis has been performed (Arisue et al. 2012; 
Brayton et al. 2007; Cai et al. 2003; Gardner et al 2005; Lau et al. 2009; Williamson et al. 2001), and the results recorded in gene databases. These data revealed that features of the apicoplast genome are fairly well conserved between species, although they may also differ. The part of the apicoplast DNA sequence encoding the 2 rRNA genes $(r r l, r r s)$ as well as genes for 9 tRNA species (trnA(UGC), $\operatorname{trn} I(\mathrm{GAU})$, $\operatorname{trn} L(\mathrm{UAG}), \operatorname{trn} M(\mathrm{CAU}), \operatorname{trn} N(\mathrm{GUU}), \operatorname{trn} R(\mathrm{ACG})$, $\operatorname{trn} R(\mathrm{UCU}), \operatorname{trn} T(\mathrm{UGU})$, and $\operatorname{trn} V(\mathrm{UAC}))$ are duplicated to form an inverted repeat (IR) in all Plasmodium species studied, except for the rodent malaria parasite Plasmodium chabaudi chabaudi (Arisue et al. 2012; Sato et al. 2013). An IR with identical features exists even in coccidian apicoplast sequences, although the corresponding sequence is not duplicated in piroplasmids. These findings suggest that the apicoplast IR was present in the common ancestor of all extant apicomplexan species and that one copy of the duplicated IR units was independently lost in the branches corresponding to piroplasmids and P. chabaudi chabaudi (Sato et al. 2013).

The apicomplexan genus Leucocytozoon consists of species which parasitize birds (Valkiunas 2005). Among them, $L$. caulleryi, which can cause fatal malaria-like symptoms in the chicken (Gallus gallus domesticus), is one of the species with the greatest economic impact, and it is distributed mainly throughout Asian countries including Japan (Morii et al. 1981; Morii 1992; Yu and Wang 2001). Genomic information could contribute not only to understanding the biological features of pathogens but also to the development of control procedures for infection, such as genetically recombinant vaccines or protein-targeted drugs. Trials to induce production

Table 1 Comparison of apicoplast genomes

\begin{tabular}{|c|c|c|c|c|c|c|c|}
\hline Species & $\begin{array}{l}\text { Leucocytozoon } \\
\text { caulleryi } \text { Niigata }\end{array}$ & $\begin{array}{l}\text { Plasmodium } \\
\text { falciparum } \mathrm{C} 10\end{array}$ & $\begin{array}{l}\text { Plasmodium chabaudi } \\
\text { chabaudi } \mathrm{CB}\end{array}$ & $\begin{array}{l}\text { Toxoplasma } \\
\text { gondii RH }\end{array}$ & $\begin{array}{l}\text { Eimeria tenella } \\
\text { Penn State }\end{array}$ & $\begin{array}{l}\text { Theileria parva } \\
\text { Muguga }\end{array}$ & $\begin{array}{l}\text { Babesia } \\
\text { bovis T2Bo }\end{array}$ \\
\hline $\begin{array}{c}\text { Complete/ } \\
\text { partial }\end{array}$ & Complete & Partial & Complete & Complete & Complete & Complete & Complete \\
\hline Size (bp) & 34,779 & 34,682 & 29,623 & 34,996 & 34,750 & 39,579 & 33,351 \\
\hline $\mathrm{A}+\mathrm{T}(\%)$ & 85.1 & 86.9 & 86.3 & 78.6 & 79.4 & 80.5 & 78.2 \\
\hline $\mathrm{IR}^{\mathrm{Z}}$ & $+^{\mathrm{a}}$ & + & - & + & + & - & - \\
\hline Protein $^{\mathrm{b}, \mathrm{c}}$ & 30 & 31 & 31 & 29 & 29 & $32^{\mathrm{d}}$ & $30^{\mathrm{e}}$ \\
\hline $\operatorname{clp} C^{\mathrm{b}}$ & 1 & 1 & 1 & 1 & 1 & 2 & 2 \\
\hline $\operatorname{sufB}$ & + & + & + & + & + & - & - \\
\hline rpl23 & + & + & + & - & - & - & - \\
\hline ORF91 & - & + & + & - & - & - & - \\
\hline rRNA $^{b}$ & $2^{\mathrm{f}}$ & $2^{\mathrm{f}}$ & 2 & $2^{\mathrm{f}}$ & $2^{\mathrm{f}}$ & 2 & 2 \\
\hline $\mathrm{tRNA}^{\mathrm{b}}$ & $25^{\mathrm{g}}$ & $25^{\mathrm{g}}$ & $26^{\mathrm{h}}$ & $24^{\mathrm{g}}$ & $24^{\mathrm{g}}$ & $24^{\mathrm{i}}$ & 24 \\
\hline $\operatorname{trn} G(\mathrm{ACC})$ & + & + & + & - & - & - & - \\
\hline $\begin{array}{l}\text { Intron in } \\
\quad \operatorname{trnL} \text { (UUA) }\end{array}$ & + & + & + & + & - & + & + \\
\hline $\begin{array}{l}\text { In-frame stop } \\
\text { codon }^{j}\end{array}$ & - & - & - & + & + & - & - \\
\hline Coding strand & Both & Both & Both & Both & Both & One & One \\
\hline $\begin{array}{r}\text { Accession } \\
\text { number }\end{array}$ & AP013071 & X95275, X95276 & HF563595 & U87145 & AY217738 & NC_007758 & NC_011395 \\
\hline
\end{tabular}

${ }^{\mathrm{z}}$ Inverted repeat

${ }^{\mathrm{a}}+$ present, - absent

${ }^{\mathrm{b}}$ Number of different products encoded

${ }^{\mathrm{c}}$ rpoC2 considered two separate proteins ( $r p o C 2 A$ and $r p o C 2 B$ )

${ }^{\mathrm{d}}$ Excluding those specified by 12 repetitive genes predicted between $r p o C 1$ and $r p o C 2 A$

${ }^{\mathrm{e}}$ Excluding repetitive gene products from BBOV_V000300, BBOV_V000310, BBOV_V000320, BBOV_V000180, BBOV_V000200, and BBOV V000210

${ }^{\mathrm{f}}$ The gene for each is present in IR and duplicated

${ }^{\mathrm{g}}$ Genes specifying 9 tRNA species (tRNA-Ala(UGC), $\operatorname{Arg}(\mathrm{ACG}), \operatorname{Arg}(\mathrm{UCU}), \operatorname{Asn}(\mathrm{GUU}), \mathrm{Ile}(\mathrm{GAU}), \mathrm{Leu}(\mathrm{UAG}), \mathrm{Met}(\mathrm{CAU}), \mathrm{Thr}(\mathrm{UGU}), \operatorname{and}$ Val(UAC)) are present in IR and duplicated

${ }^{\mathrm{h}}$ Two genes encode different versions of tRNA-Thr. The gene for tRNA-Met is duplicated

${ }^{\mathrm{i}}$ Five genes encode the same tRNA-Met(CAU)

${ }^{\mathrm{j}}$ Excluding the hypothetical codon connecting rpoC2A and $r p o C 2 B$ 
of protective antibodies against $L$. caulleryi infection by inoculation of chickens with recombinant antigens have been reported (Ito and Gotanda 2004; Ito et al. 2005; Morii et al. 1996). We previously reported the complete mitochondrial DNA sequence as well as the structure and partial nucleotide sequence of the apicoplast DNA of $L$. caulleryi (Omori et al. 2008). However, the entire genome should reveal further understanding of this parasite's biology. In this study, we determined the complete nucleotide sequence of the apicoplast DNA, including the region connecting the two IR units. This is the first such report of a haemosporidian IR-positive apicoplast DNA sequence.

\section{Materials and methods}

PCR amplification and Sanger sequence analysis of genomic DNA

Total L. caulleryi genomic DNA was prepared from the blood of infected chickens (designated the Niigata strain), which were obtained from a poultry farm in Niigata Prefecture, Japan. A series of PCR primers was designed to match the Plasmodium spp. plastid DNA sequences obtained from a genetic database. With these primers, sections of the plastid DNA were amplified from the total $L$. caulleryi genomic DNA preparation by polymerase chain reaction (PCR) and

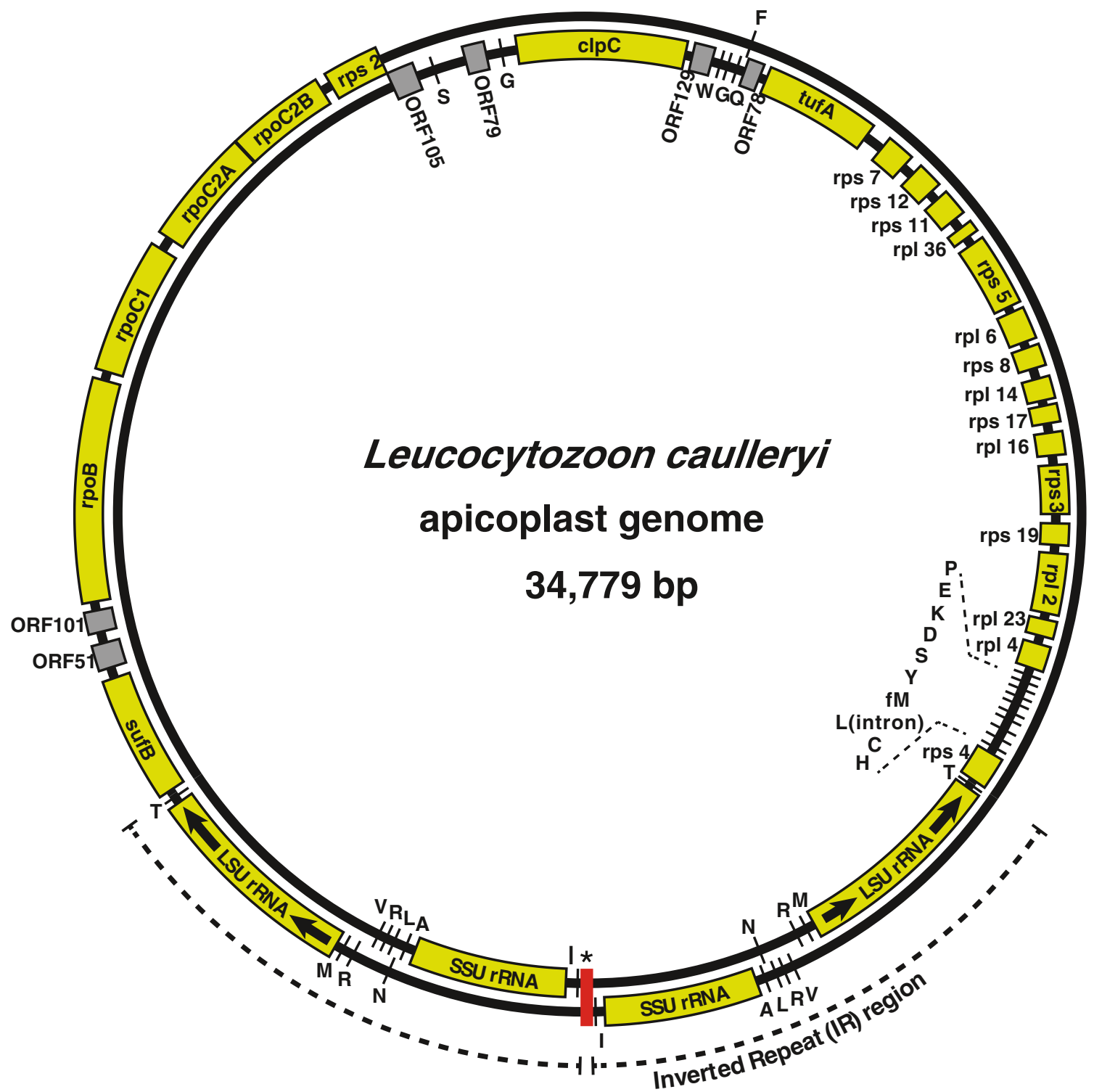

Fig. 1 Map of the L. caulleryi plastid genome. Concentric circles represent the circular double-stranded DNA genome, and each gene annotated in the DNA sequence is illustrated on either of the two circles depending on the direction of transcription (outer circle clockwise; inner circle anticlockwise). Yellow boxes represent genes specifying either a protein or an rRNA, whereas lines and gray boxes indicate tRNA-coding genes or hypothetical open reading frames, respectively. Each inverted repeat (IR) unit is indicated by the outermost dotted arcs, and the asymmetric 13-bp sequence separating the two IR units is marked with an asterisk 
the nucleotide sequence of each PCR fragment was determined directly by Sanger sequencing as described previously (Omori et al. 2008).

High throughput sequence analysis of genomic DNA

A library for high-throughput sequencing (HTS) was prepared from the parasite DNA using the Paired End Sample Prep Kit (Illumina) and analyzed by the Illumina method on a Genome Analyzer IIx (Illumina). From the HTS data obtained, reads matching the trnI gene sequence at the end of the IR unit were searched for by using BLASTN to query the NCBI database. Obtained reads were aligned using Clustal $X$ (Larkin et al. 2007) to extend the nucleotide sequences in locations where the PCR direct sequencing method described above was insufficient.

The position and the anticodon of each tRNA gene encoded by the $L$. caulleryi plastid DNA sequence were predicted by the tRNAscan-SE server (http://lowelab.ucsc. edu/tRNAscan-SE/). All other genes were manually annotated based on homology to P. falciparum.

\section{Phylogenetic analysis}

Phylogeny of the plastid genomes of $L$. caulleryi and 7 other apicomplexan species (P. falciparum, P. gallinaceum, $P$. berghei, T. parva, B. bovis, E. tenella, and T. gondii) as well as Chromera velia, which was chosen as the out-group, was deduced from the amino acid sequences that represent the genomes. The representative sequences, which were 2,478 residues long, were created by concatenating the amino acid sequences of the products of the following 10 genes: $r p l 2, r p l$ 6, rpl 14, rpl 16, rps 2, rps 3, rps 11, rps 12, tufA, and rpoB. An alignment of these sequences was created using Clustal W (Larkin et al. 2007), and the phylogeny of these sequences was analyzed using MEGA5 (http://www.megasoftware.net) by the maximum likelihood method with the JTT $+\mathrm{F}+\Gamma$ model. Bootstrap analysis with 1,000 replicates was performed to estimate the confidence of the tree topology.

\section{Results}

We determined the complete nucleotide sequence of the Leucocytozoon plastid DNA for the first time. The $L$. caulleryi plastid DNA was $34,779 \mathrm{bp}$, and its A+T content was $85.1 \%$ (Table 1$)$. These values were within the range of other plastid DNA data previously reported. Like the plastid DNA of Plasmodium spp. and the coccidians, the plastid DNA of $L$. caulleryi had an inverted repeat (IR) that occupied about $1 / 3$ of the unit sequence (Fig. 1). We had no problem in amplifying the majority of the plastid DNA by PCR. However, the sequence connecting the two IR units at the end closest to the tRNA-Ile gene was the exception; we had no success in obtaining PCR fragments that contained the short sequence (data not shown). It is possible that this region of the $L$. caulleryi plastid DNA forms a peculiar structure that interferes with extension of the DNA strand in PCR, similar to the "tip region" present between the two IR units of the E. tenella plastid DNA (Cai et al. 2003). Therefore, we analyzed the total genomic DNA extracted from the parasite preparation by whole genome sequencing with the Illumina platform, and we searched for reads corresponding to the end of the IR unit in these HTS data. These identified reads filled the gap between the two IR units, which was found to be only $13 \mathrm{bp}$, allowing us to finally obtain the complete plastid nucleotide sequence.

Each IR unit, which was 5,253 bp, encoded one gene each of large and small ribosomal RNA subunits ( $r r l$ and $r r s$, respectively) as well as 9 tRNA genes (trnA(UGC), $\operatorname{trn} I(\mathrm{GAU}), \operatorname{trn} L(\mathrm{UAG}), \operatorname{trn} M(\mathrm{CAU}), \operatorname{trn} N(\mathrm{GUU})$, $\operatorname{trn} R(\mathrm{ACG}), \operatorname{trn} R(\mathrm{UCU}), \operatorname{trn} T(\mathrm{UGU})$, and $\operatorname{trn} V(\mathrm{UAC}))$, but no protein-coding gene. These characteristics are conserved across all presently studied apicomplexan species with IRpositive apicoplast DNA.

There were 30 total protein-coding genes annotated in the L. caulleryi plastid DNA sequence. These genes, as well as 16 tRNA genes, were encoded outside the IR region. Both the content of the genome itself and the arrangement of each gene on the DNA were remarkably highly conserved between $L$. caulleryi and $P$. falciparum. The only difference between the two was the presence of the ORF91 gene, which is missing from the $L$. caulleryi genome but encoded between rps 5 and rpl36 (Wilson et al. 1996) in P. falciparum DNA. Interestingly, this open reading frame (ORF) is also absent from coccidian and piroplasmid plastid genomes (Table 1), despite the fact that ORF91 in each Plasmodium species specifies a fairly conserved amino acid sequence (data not shown).

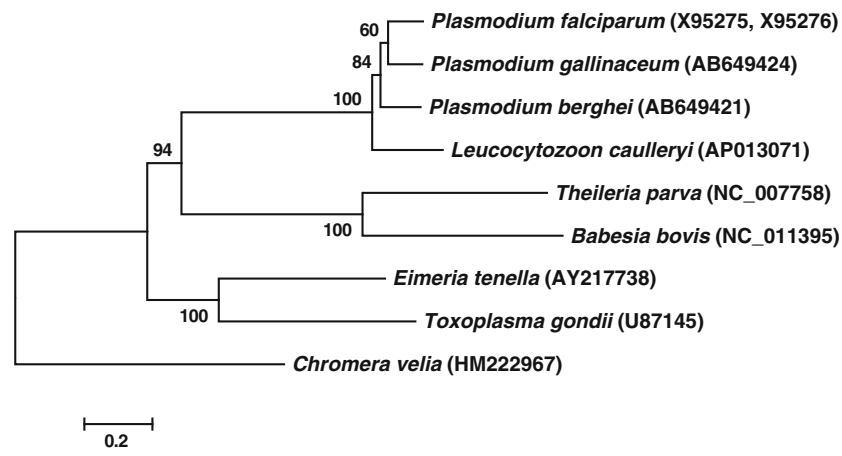

Fig. 2 Phylogeny of the apicoplast genomes. Amino acid sequences specified by the 10 selected plastid-encoded genes were concatenated for each species, and the phylogeny was analyzed by the maximum likelihood method with the JTT $+\mathrm{F}+\Gamma$ model to obtain the dendrogram. Numbers at nodes indicate bootstrap values from 1,000 replicates. The scale bar indicates 0.2 substitutions per site. The accession numbers of the nucleotide sequence data, from which the amino acid sequences used in the analysis were deduced, are given in parentheses after the name of each taxon 
Phylogenetic analysis of the concatenated amino acid sequences of 10 gene products $(2,478$ residues) suggested a close relationship between $L$. caulleryi and Plasmodium (Fig. 2). This finding, along with similarities in both gene content and arrangement of genes on the DNA, suggests that the $L$. caulleryi plastid has similar functions to that of Plasmodium.

\section{Discussion}

By analogy to P. falciparum DNA (Williamson et al. 2002), we had speculated that most of the L. caulleryi plastid DNA exists as circular DNA rather than linear multimers, as in $T$. gondii (Williamson et al. 2001). This organization, together with the presence of a set of inverted repeats was confirmed by the sequence analysis.

Phylogenetic studies using apicoplast genome sequences have been used to examine relationships between members of the Apicomplexa. For example, Oborník and colleagues (2002) used $894 \mathrm{nt}$ apicoplast DNA sequences corresponding to part of the rrs gene and showed this provide a useful tool to analyze Apicomplexa and distinguish between coccidian and haemosporidian parasites. Our use of concatenated amino acid sequences extends this analysis and suggests a close relationship between L. caulleryi and Plasmodium .

Both the organization of the genes and the phylogenetic analysis of amino acid sequences suggested that the $L$. caulleryi plastid DNA is very similar to that of Plasmodium spp. One notable difference is the absence of ORF91 from the $L$. caulleryi plastid genome. It is as yet unknown whether the missing gene has been translocated to the nuclear genome so that its protein product is imported into the plastid; however, the absence of ORF91 in the organellar genome suggests that, unlike Plasmodium spp., non-Plasmodium species lack the plastid function in which the ORF91 gene product is involved.

As with other apicoplast DNA, the rpoC2 gene in $L$. caulleryi specifying a specific subunit of the multi subunittype DNA-dependent RNA polymerase was interrupted by an in-frame UGA codon. Here we annotated the two juxtaposing ORFs separately as $r p o C 2 A$ and $r p o C 2 B$, although these might be read through in translation to produce a continuous polypeptide as hypothesized for rpoC2 in P. falciparum (Wilson et al. 1996). Unlike coccidians (http://roos.bio. upenn.edu/ rooslab/jkissing/toxomap.html, Cai et al. 2003), no other apparent in-frame stop codon has been predicted in the plastid genome of $L$. caulleryi.

The plastid, which is known to provide the platform for critical metabolic processes such as isoprenoid biosynthesis, has been recognized as a promising target for drugs to inhibit the growth of Plasmodium spp., and understanding its metabolic functions may aid in designing drugs that prevent the infection and transmission of $L$. caulleryi. Elucidation of its genome structure is an important step along this pathway.

The apicoplast genome of $L$. caulleryi is much larger than the mitochondrial genome of this species (Omori et al. 2008). In the absence of the apicoplast sequence, phylogenetic analysis and genetic typing of Leucocytozoon had been generally carried out using mitochondrial sequence such as that of the cytochrome $b$ gene alone (Imura et al. 2010; Ortego and Cordero 2009). Now we have established the complete nucleotide sequence of the Leucocytozoon apicoplast genome, this newly available information will contribute to improving the accuracy of both phylogenetic analysis and genetic typing of apicomplexan parasites including Leucocytozoon .

Acknowledgments This study was supported in part by a Grant-in-Aid for Scientific Research (No. 21580406) from the Japan Society for the Promotion of Science and the Strategic Research Base Development Program "International research on epidemiology of zoonoses and training for young researchers" matching fund subsidy from the Ministry of Education, Culture, Sports, Science and Technology of Japan. Work in the Holder laboratory was supported by the UK Medical Research Council (File References U117532067 and U117584270).

Open Access This article is distributed under the terms of the Creative Commons Attribution License which permits any use, distribution, and reproduction in any medium, provided the original author(s) and the source are credited.

\section{References}

Arisue N, Hashimoto T, Mitsui H, Palacpac NM, Kaneko A, Kawai S, Hasegawa M, Tanabe K, Horii T (2012) The Plasmodium apicoplast genome: conserved structure and close relationship of P. ovale to rodent malaria parasites. Mol Biol Evol 29:2095-2099

Brayton KA, Lau AO, Herndon DR, Hannick L, Kappmeyer LS, Berens SJ, Bidwell SL, Brown WC, Crabtree J, Fadrosh D, Feldblum T, Forberger HA, Haas BJ, Howell JM, Khouri H, Koo H, Mann DJ, Norimine J, Paulsen IT, Radune D, Ren Q, Smith RK Jr, Suarez CE, White O, Wortman JR, Knowles DP Jr, McElwain TF, Nene VM (2007) Genome sequence of Babesia bovis and comparative analysis of apicomplexan haemoprotozoa. PLoS Pathol 3:1401-1413

Cai X, Fuller AL, McDougald LR, Zhu G (2003) Apicoplast genome of the coccidian Eimeria tenella. Gene 321:39-46

Foth BJ, McFadden GI (2003) The apicoplast: a plastid in Plasmodium falciparum and other Apicomplexan parasites. Int Rev Cytol 224: $57-110$

Gardner MJ, Bishop R, Shah T, de Villiers EP, Carlton JM, Hall N, Ren Q, Paulsen IT, Pain A, Berriman M, Wilson RJM, Sato S, Ralph SA, Mann DJ, Xiong Z, Shallom SJ, Weidman J, Jiang L, Lynn J, Weaver B, Shoaibi A, Domingo AR, Wasawo D, Crabtree J, Wortman JR, Haas B, Angiuoli SV, Creasy TH, Lu C, Suh B, Silva JC, Utterback TR, Feldblyum TV, Pertea M, Allen J, Nierman WC, Taracha ELN, Salzberg SL, White OR, Fitzhugh HA, Morzaria S, Venter JC, Fraser CM, Nene V (2005) Genome sequence of Theileria parva, a bovine pathogen that transforms lymphocytes. Science 309:134-137

Imura T, Sato Y, Ejiri H, Tamada A, Isawa H, Sawabe K, Omori S, Murata K, Yukawa M (2010) Molecular identification of blood source animals from black flies (Diptera: Simuliidae) collected in the alpine regions of Japan. Parasitol Res 106:543-547 
Ito A, Gotanda T (2004) Field efficacy of recombinant R7 vaccine against chicken Leucocytozoonosis. J Vet Med Sci 66:483-487

Ito A, Gotanda T, Kobayashi S, Kume K, Sugimoto C, Matsumura T (2005) Increase of antibody titer against Leucocytozoon caulleryi by oral administration of recombinant R7 antigen. J Vet Med Sci 67: 211-213

Janouskovec J, Horák A, Oborník M, Lukes J, Keeling PJ (2010) A common red algal origin of the apicomplexan, dinoflagellate, and heterokont plastids. Proc Natl Acad Sci U S A 107:10949-10954

Köhler S, Delwiche CF, Denny PW, Tilney LG, Webster P, Wilson RJM, Palmer JD, Roos DS (1997) A plastid of probable green algal origin in Apicomplexan parasites. Science 275:1485-1489

Larkin MA, Blackshields G, Brown NP, Chenna R, McGettigan PA, McWilliam H, Valentin F, Wallace IM, Wilm A, Lopez R, Thompson JD, Gibson TJ, Higgins DG (2007) Clustal W and Clustal X version 2.0. Bioinformatics 23:2947-2948

Lau AO, McElwain TF, Brayton KA, Knowles DP, Roalson EH (2009) Babesia bovis: a comprehensive phylogenetic analysis of plastidencoded genes supports green algal origin of apicoplasts. Exp Parasitol 123:236-243

McFadden GI (2011) The apicoplast. Protoplasma 248:641-650

Morii T (1992) A review of Leucocytozoon caulleryi infection in chickens. J Protozool Res 2:128-133

Morii T, Shiihara T, Lee YC, Manuel MF, Nakamura K, Iijima T, Hoji K (1981) Seroimmunological and parasitological surveys of Leucocytozoon caulleryi infection in chickens in several Asian countries. Int J Parasitol 11:187-190

Morii T, Matsui T, Fujino T, Kobayashi F, Tsuji T (1996) Immunogenicity of Leucocytozoon caulleryi sporozoites and their reactivity with specific immune sera. Parasitol Res 82:454-458

Oborník M, Jirků M, Slapeta JR, Modrý D, Koudela B, Lukes J (2002) Notes on coccidian phylogeny, based on the apicoplast small subunit ribosomal DNA. Parasitol Res 88:360-363

Omori S, Sato Y, Hirakawa S, Isobe T, Yukawa M, Murata K (2008) Two extra chromosomal genomes of Leucocytozoon caulleryi; complete nucleotide sequences of the mitochondrial genome and existence of the apicoplast genome. Parasitol Res 103:953-957

Ortego J, Cordero PJ (2009) PCR-based detection and genotyping of haematozoa (Protozoa) parasitizing eagle owls, Bubo bubo. Parasitol Res 104(2):467-470

Ralph SA, van Dooren GG, Waller RF, Crawford MJ, Fraunholz MJ, Foth BJ, Tonkin CJ, Roos DS, McFadden GI (2004) Tropical infectious diseases: metabolic maps and functions of the Plasmodium falciparum apicoplast. Nat Rev Microbiol 2:203-216

Sato S, Sesay AK, Holder AA (2013) The unique structure of the apicoplast genome of the rodent malaria parasite Plasmodium chabaudi chabaudi. PLoS One 8:e61778. doi:10.1371/journal. pone. 0061778

Valkiunas G (2005) Avian malaria parasites and other Haemosporidia. CRC, Boca Raton

Williamson DH, Denny PW, Moore PW, Sato S, McCready S, Wilson RJM (2001) The in vivo conformation of the plastid DNA of Toxoplasma gondii: implications for replication. J Mol Biol 306: $159-168$

Williamson DH, Preiser PR, Moore PW, McCready S, Strath M, Wilson RJM (2002) The plastid DNA of the malaria parasite Plasmodium falciparum is replicated by two mechanisms. Mol Microbiol 45: 533-542

Wilson RJM, Denny PW, Preiser PR, Rangachari K, Roberts K, Roy A, Whyte A, Strath M, Moore DJ, Moore PW, Williamson DH (1996) Complete gene map of the plastid-like DNA of the malaria parasite Plasmodium falciparum. J Mol Biol 261:155-172

Yeh E, DeRisi JL (2011) Chemical rescue of malaria parasites lacking an apicoplast defines organelle function in blood-stage Plasmodium falciparum. PLoS Biol 9:e1001138. doi:10.1371/journal.pbio. 1001138

Yu CY, Wang JS (2001) Role of chicken serum in inhibiting Leucocytozoon caulleryi development in Culicoides arakawae infected by membrane-feeding of infective blood meals. Parasitol Res 87:698-701 